\title{
CONTENT-BASED INSTRUCTION APPROACH IN INSTRUCTIONAL MULTIMEDIA FOR ENGLISH LEARNING
}

\author{
Rizki Farani \\ State Islamic University of Sunankalijaga
}

\begin{abstract}
Content-based Instruction (CBI) is an approach in English learning that integrates certain topic and English learning objectives. This approach focuses on using English competencies as a "bridge" to comprehend certain topic or theme in English. Nowadays, this approach can be used in instructional multimedia to support English learning by using computer. Instructional multimedia with computer system refers to the sequential or simultaneous use of variety of media formats in a given presentation of selfstudy program in a computer. Instructional media combines several aspects such as text, pictures, graphic, sound and video. There are many English materials that are presented in a computer display by combining all aspects of multimedia. This method can help learner to understand the material better by visualizing the concept.

In integrating CBI approach in instructional multimedia by using computer, there are two important aspects in creating effective multimedia, such as displaying reading text and integrating all English skills. In displaying reading text, $\mathrm{CBI}$ approach play important role in presenting reading passages about certain topic based on students' interest and multimedia aspects also play significant role in visualizing all concepts and vocabularies from the reading passage. This paper will discuss the integration of CBI approach in instructional multimedia for English learning deeply by presenting the basic concept and providing some examples of instructional multimedia display.
\end{abstract}

Keywords: Content-Based Instruction Approach, Instructional Multimedia, English Learning 


\section{INTRODUCTION}

Content-based instruction (CBI) is one of the approaches in English learning. This approach refers to second language teaching which is organized around the content or information that students will acquire, rather than around linguistic or type of syllabus (Richards \& Rogers, 2006: 204). In CBI, students learn English by building knowledge and English competencies at the same time, for instance: students learn how to use different tenses from reading passages about Australia. In this instructional process, students will learn two things; a) tenses and b) Australia. Students will gain more knowledge about other countries while learning grammar. This approach gives positive atmosphere in the lass because students will learn English competencies in fun and flexible situation. This approach has a great potential to improve students' motivation in learning English.

However, well-planned learning process needs to be supported by effective media to present the material. Nowadays, more teachers choose multimedia with computer-supported learning to deliver English content. Multimedia refers to the sequential or simultaneous use of variety of media formats in a given presentation or self-study program (Smaldino, et.al, 2005: 141). Multimedia can present materials effectively because it consists of several aspects, such as text, images, audio, video and animation.

This paper will discuss about the integration of CBI approach in instructional multimedia to deliver English content.

\section{LITERATURE REVIEW}

\section{Content-based Instruction Approach}

Content-based Instruction (CBI) (Brinton, et.al: 1989: 1) is an approach in English language learning that integrates specific language learning goals in certain topic (Brinton, et.al: 1989: 2). This approach focuses on studying the specific knowledge through English, for instance: learning English competencies by using Islamic reading text for students in Islamic university. In this process, students will learn English through reading text and getting more information about Islamic issues.

Two basic concepts in CBI approach states that (Richards and Rodgers, 2006:207) : a) people learn a second language more successfully when they use the 
language as a means of acquiring information, rather than as an end in itself and $b$ ) CBI better reflects learner's needs for learning a second language. By integrating English competencies into interesting themes or specific information, learning English may become more engaging for students.

Two basic concepts above are supported by language theories which state that English lessons focuses on how information and meaning can be facilitated by reading text as a complete comprehension, not by individual sentences. In other words, English language learning aims to understand reading text. In addition, all English skills (Listening, Speaking, Reading and Writing) are integrated in a single topic to help students comprehend complete skills. Finally, learning languages always ??has a specific purpose and a key goal that focuses on using language to convey meaning (Richards and Rodgers, 2006:208).

Brinton et.al (1989:14-16) outlines three types of CBI approach, such as sheltered model, adjunct model and theme-based models. Sheltered model is sheltered course that consists of content course taught in the second language to a segregated group of learners by a content area specialist (Brinton et.al , 1989: 15). Meanwhile, adjunct model links two courses, language course and content course. It needs two specialists, language specialist and content course. In terms of themebased model, it is a common model for Indonesia because this model is used to teach English as a second language, whether small or large classes. This model can be used by the teacher or lecturer in English studies or expert specialists by developing learning material based on learner interest.

CBI approach gives several positive impacts in English learning (Peachey, 2003:1), such as:

a. Learning process can be more interesting. Learners can use language to do things, related to their learning objectives so that learners will be more independent and confident.

b. Learners can develop their own knowledge to support their academic needs.

c. Learners can develop academic skills such as collecting data, summarizing and analyzing.

d. Learners will be trained to retrieve information from a variety of sources, evaluate and restructure information in order to develop their thinking skills that can be used to study various sciences.

e. Working group, which is one of the learning methods in CBI, can help learners to improve their communication skill to gain so a high social skill. 
However, CBI still has some challenges (Peachey, 2003:2) for example:

a. Learners are sometimes confused about how they improve the language skills because this approach does not teach grammar specifically.

b. Learners are more likely to use the first language rather than target language.

c. Sometimes it is difficult for teachers to find learning resources for elementary students

d. Some learners will be directly copied the information from reading text to answer questions or discuss the topic. In fact, this approach actually wants to help students to be able to draw conclusions and make analysis from the text with their own words.

Some solutions are offered to encounter the challenges. Peachey (2003:2) suggests that teachers can provide some practices to ensure that they are able to understand English grammar. Teachers also can give rationales in using English or combine the usage of first language and target language, for example: teachers can give reading text in students' vernacular language, but the discussion should be in English or vice versa. This strategy is used primarily for elementary level. Finally, teachers can provide a well-organized material to help students understand the content, for instance: teachers give reading passages, complete with related pictures, charts, table or diagrams.

\section{CBI in Instructional Multimedia}

Based on the description about CBI concept, it is concluded that CBI approach has several characteristic, such as:

a. CBI approach uses reading activity as the main resources of learning. It uses reading passages, essays, articles or journals to describe English competencies, for example: learning how to identify conditional sentences by reading an article about education.

b. CBI approach integrates other English skills (Listening, Speaking and Writing in reading activity).

Now, the big question is: "how to visualize the characteristics of $\mathrm{CBI}$ into instructional multimedia?". Multimedia refers to the sequential or simultaneous use of variety of media formats in a given presentation of self-study program. Multimedia combines several aspects such as text, pictures, graphic, sound and video. The goal of multimedia is to immerse the learner in a multimedia sensory 
experience to promote learning. Today, multimedia is used in the format of computer instructional program (Smaldino, 2005: 141). Computer is used to support the utilization of multimedia in learning process because computer provides virtually response to student input. It also provides capacity to store and manipulate information. There are two applications of computer in instruction: computer-assisted instruction (CAI) and computer-managed instruction (CMI). In CAI students interact directly with the computer as part of the instructional activity. Meanwhile, CMI helps both instructor and students in maintaining information about students and in guiding instruction (Smaldino, 2005: 110).

There are two important aspects in creating effective multimedia and integrating the characters of content-based instruction in computer learning model, such as:

\section{Displaying reading Text}

Reading passages can be visualized by considering some multimedia guidance. Azhar Arsyad (2011: 99-100) explains several multimedia designs for reading text in computer display:

a. Reading text in a computer screen should have appropriate space between sentences, for example: use double line spacing to make it easier to read.

b. Use normal font and combine uppercase and lowercase based on their function, for example: use capital letter in front of Places' name, title, sub title, etc.

c. Use seven to ten words per line because it will be easier to read short sentences.

d. Place the text in the center of the screen.

e. Consistent with style and writing format.

f. Use certain characters in the title and key words, such as bold, underline or italics.

g. Use table or line to separate text and images, text and graphs or other visual representation.

Other multimedia elements that should be provided to complete the text are (Phillips, 1997: 82-86):

1. Line. The line is an important element in the design of multimedia to determine the focus of eyes when looking at a computer screen.

2. Shape. Elements form has its own function in the use of text and symbols. There are three basic forms of multimedia design: a square, rectangle and 
triangle. Square shape is usually associated with text, rectangular shape is associated with the title and triangle shape is associated with symbol or logo.

3. Texture. Use soft color for reading text to create a good balance between words and screen display.

4. Balance. Balance is an element that contains all combinations of multimedia design from the line, form, texture, space, color and text. To ensure that this balance can be achieved in multimedia design, a designer can try to make a draft on a piece of paper to visualize the design.

5. Space. Space can create positive and negative space elements. Positive space is the space in which an object is placed while negative space is the space element around the object. These both elements are very important in order to view an object from different angles to create a better perspective.

6. Color. Color can produce a good effect in multimedia design, but designer should consider about how a color can be related to the topic.

7. Text. Text in multimedia design is divided into two categories: body text and title text. Body text forms the main part of the text that contains information. The font size should be small, clear and easy to read. In addition, font size in one screen should be limited to two types of fonts. If the design requires a variation of text, a designer can use bold, italic, upper case or change the color.

\section{Integrating all English skills}

English skills can be visualized by adding more multimedia elements in the reading text display. The elements are:

1. Picture. Picture visualizes abstract concepts in the material. However, choosing appropriate picture is necessary to create an effective presentation. Pictures for instructional multimedia should relevant to the topic. It is also simple and realistic (Anitah: 2010: 9). Computer-supported learning presentation needs pictures that have a large size. Pictures with a large size are easy to be customized into different size according to computer display.

2. Sound. The audio effect should enhance the presentation of the content (Lee \& Owens, 2004: 174). The sound should be clear and easy to listen by using volume control. It had better to choose audio based on the topic; either it is song, conversation, speech or lecture. 
3. Video. Choosing video for instructional multimedia is similar to choosing pictures. It should be relevant to the topic and easy to see (clear view). In addition, consider the duration of the video because video is a part of the whole lesson plan in the learning process, thus classroom activity cannot just focus on the video but also assessment and discussion.

4. Animation. Animation refers to a simulated motion picture depicting movement of drawn (or simulated) objects (Mayer \& Romano, 2002: 2). Animation can promote learners' understanding when used in ways that are consistent with several aspects such as presenting animation and narration simultaneously, presenting text and animation with appropriate proportion on the screen and choosing relevant animation based on the topic (Mayer \& Romano, 2002: 8).

The pictures below are several examples of reading presentation in instructional multimedia:

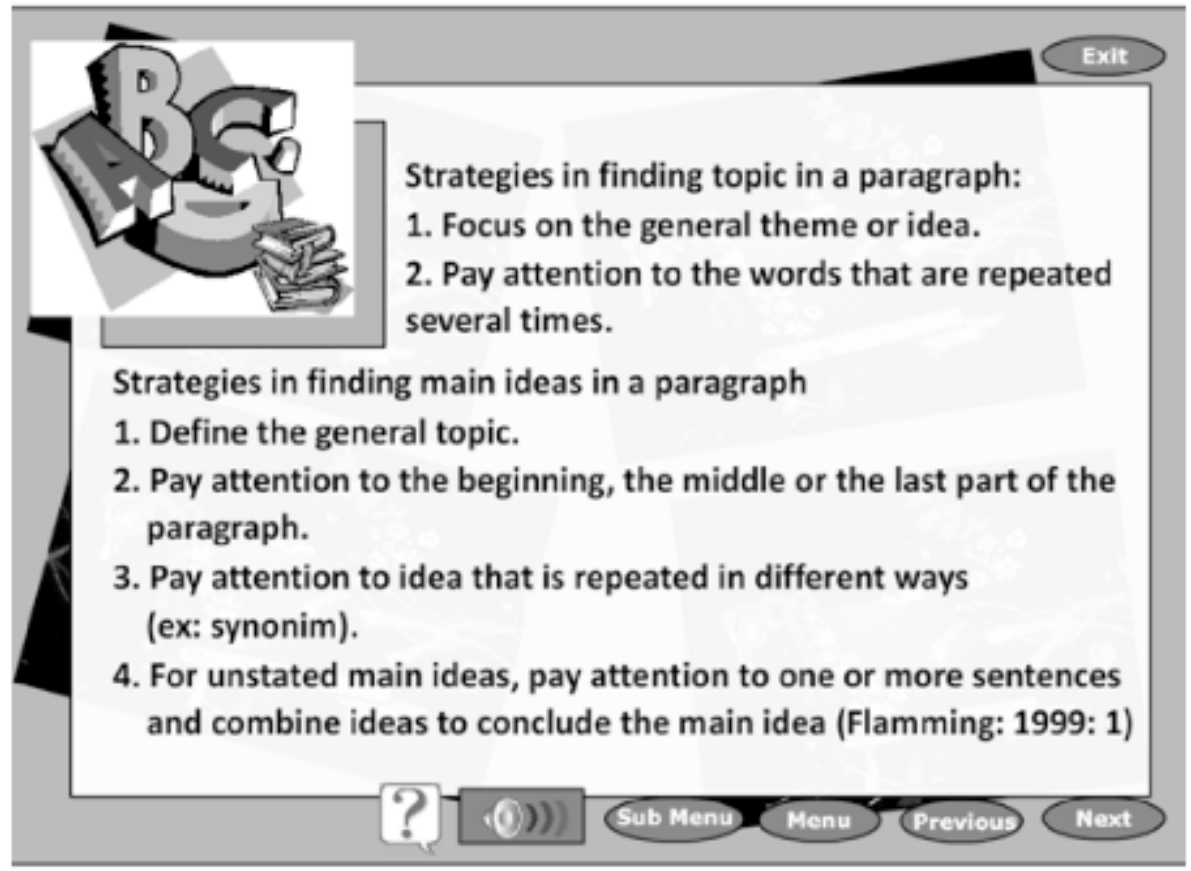

Picture 1. Media combination between text and Picture 
Picture 1 is the example of the combination between written text and pictures. The text in the diplay explains about strategies in finding topic in paragraph. Meanwhile, the picture in the display is a picture of books and alphabets. This picture is relevant to the text because it represent similar topic, that is about reading comprehension.

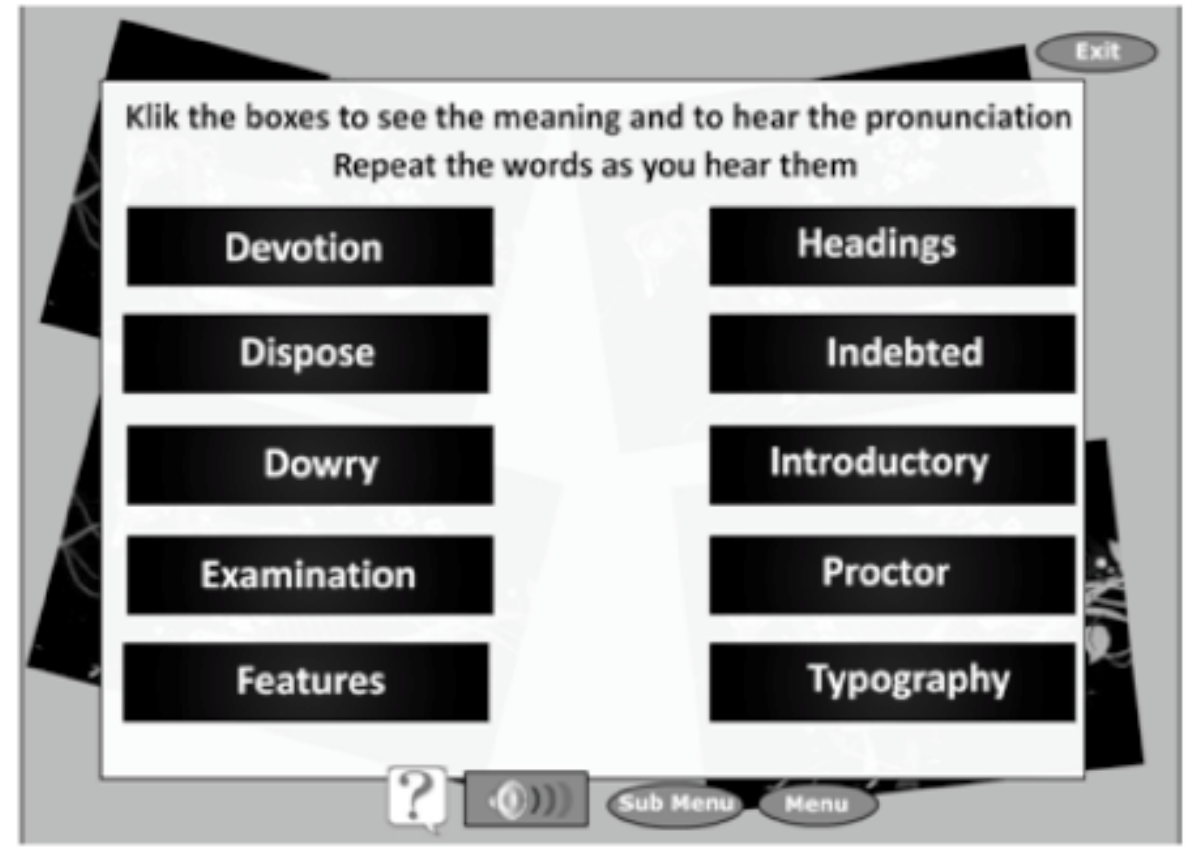

Picture 2. Media combination between text and sound

Picture 2 is the example of combination between written text (vocabularies list) and sound because the media provides pronunciation practice for learners. There are 10 vocabularies in the display. Learner should click the box of the word to hear the pronunciation. 


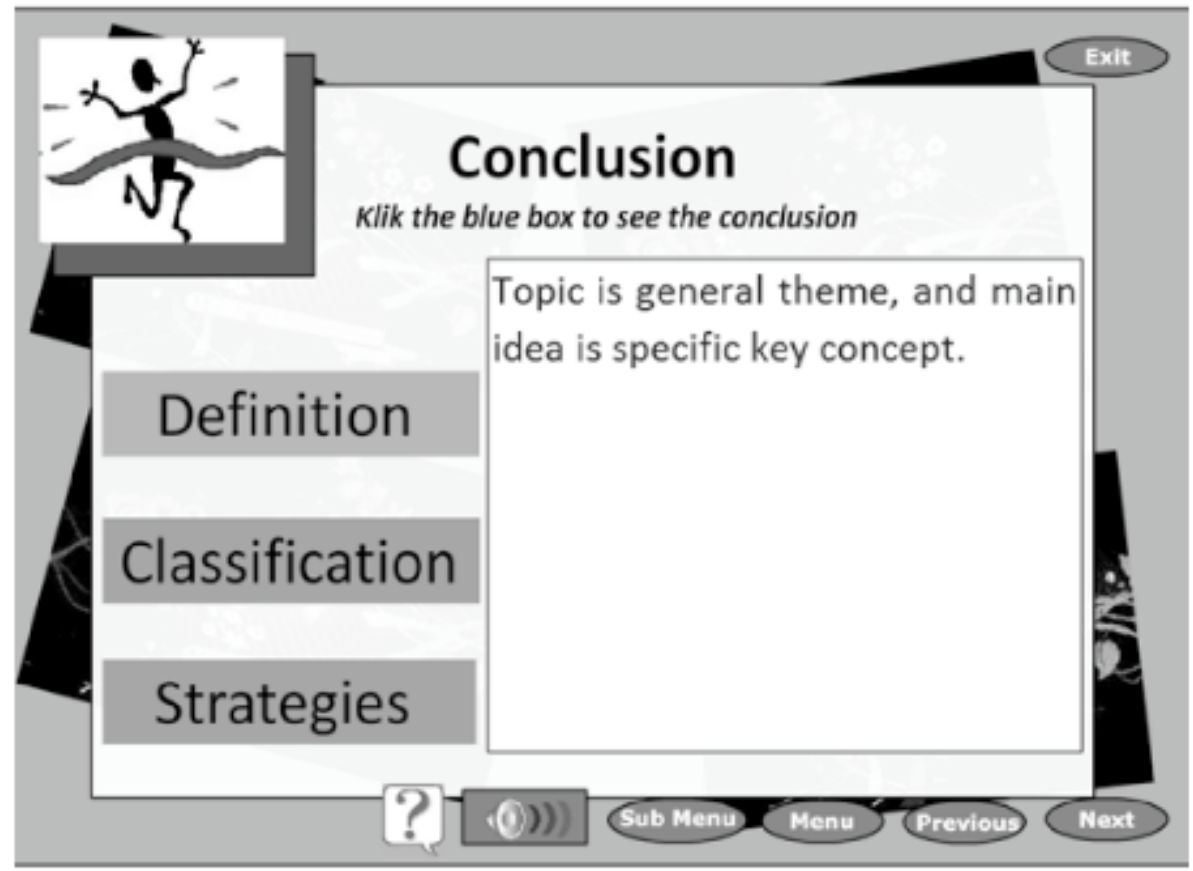

Picture 3. Media Combination between Text and Animation

Picture 3 is the example of combination between text and animation. The display presents the conclusion of the material about reading comprehension by using specific technique that is called Hypermedia Text. This technique allows learners to see additional information that pops up when they click the menu box in the left side of the display. The information will appear in the big box (right side of the display).

\section{CONCLUSION AND SUGGESTION}

By integrating CBI approach in instructional multimedia, English content can be presented effectively because it is designed based on students' interest and the material is visualized by using all aspects of multimedia such as text display, images, audio, video and animation. 
This approach can encourage students to understand the material easily, get involve in classroom activity, minimize limited structure concepts and understand English competencies as a set of skills.

\section{REFERENCES}

Anitah, Sri. (2010). Media pembelajaran. Surakarta: Yuma Pustaka.

Arsyad, Azhar. (2011). Media Pembelajaran. Jakarta: Rajawali Press.

Brinton, D.M; Wesche, M.B \& Snow, M.A. (1989). Content-based second language instruction. Boston: Heinle \& Heinle Publishers.

Lee, W.W \& Owens, D. L. (2004). Multimedia-based instructional design: computer-based training, web-based training, distance broadcast training, performance-based solutions. (2 $2^{\text {nd }}$ edition). San Fransisco: John Wiley \& Sons, Inc.

Mayer, R. E \& Moreno, R. (2002). Animation as an aid to multimedia learning. Educational psychology review. Vol. 14 No.1.

Peachey, N. (2003). Content-based instruction. Retrieved from http://www.teachingenglish.org.uk.

Phillips, R. (1997). Interactive multimedia. A practical guide for educational applications. London: Kogan page Ltd.

Richards, J. C \& Rodgers, T. S. (2006). Approaches and methods in language teaching. New York: Cambridge university press.

Smaldino, et.al. (2005). Instructional technology and media for learning. Ed. Ke8. New Jersey: Person Merrill Prentice Hall. 